\title{
Micromechanical Characterization of lake-deposited clays from the Valley of Mexico
}

\author{
${ }^{*}$ E. Palacios. F. Leyte \\ ${ }^{1}$ Instituto Mexicano del Petróleo. Eje Central Lázaro Cárdenas 152. México 07730. \\ *Correspondence should be addressed to: epalacio@imp.mx
}

\begin{abstract}
Mexico City lacustrine clays own their characteristically special mechanical behavior to a number of factors, among them to the existence of fossils, organic matter, sedimentation environment, depth, past volcanic events, basin morphology and others. SEM and TEM microscopy techniques along with $\mathrm{X}$-ray analysis and magnetic resonance allow determining their morphologic, compositional, structural, crystallographic and chemical properties. A study of lake-sedimented clays, obtained from a number of sites in the Mexico City Valley area is being undertaken to characterize clays from different sedimentary genesis and depths in this Valley. It is known that the existence of fossils ranging from millimeters down to nannofossils can determine the mechanical behavior of these sediments [1]. In Fact sedimentary processes show regions where fossils are aligned in preferential directions and planes forming discontinuities, cracks or weaken planes. Also fossils within the clay matrix create large voids (Fig. 1), which along with huge specific surfaces distinctive of clay particles allow for high to very high water contents, in the order of $300 \%$ to $500 \%$. This causes soils with high plasticity indexes very compressible and with low shear strength. The present work is aimed to contribute to the characterization of lacustrine Mexican soils, including determination of individual component properties such as bulk modulus, chemical composition, density, morphology, crystallography and nature of contacts between the soil components among others using state of the art microscopy techniques and other.
\end{abstract}

[1] Holtz D., Kovacs, W. An Introduction to Geotechnical Engineering. Prentice, 2005

[2] Marzal, R. Mazari, M. El Subsuelo de la Ciudad de Mexico. UNAM, Facultad de Ingeniería, Mexico (1959).

[3]Yashima, A., Shigematsu, H., Oka, F.. Proc. Int. Symp. On Characterization of Soft Marine Clays., Yokusura, Japan (1997). Pp 165-184. 

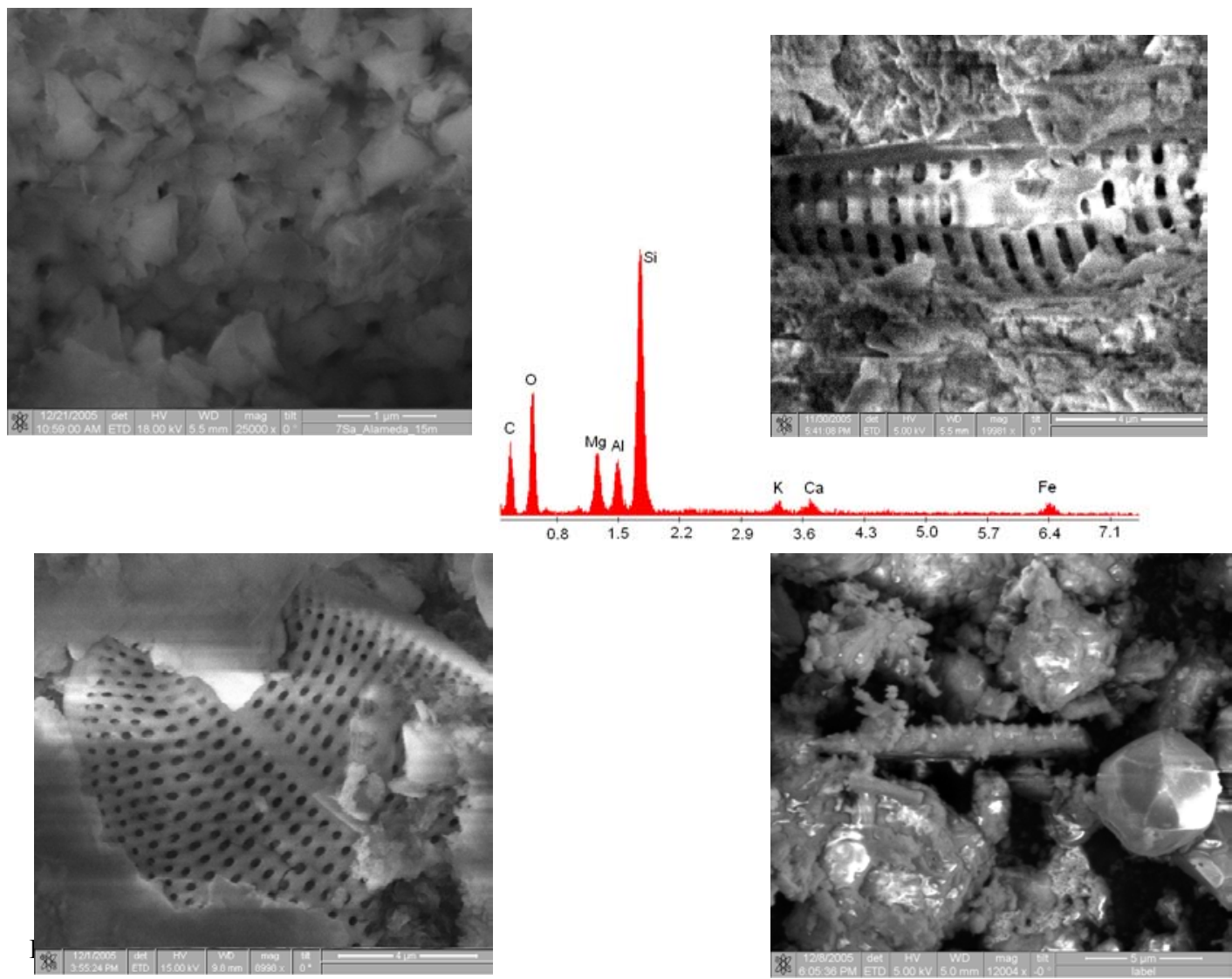